Celal Bayar University Journal of Science

\title{
Microstructural Characterisations of Welded Shape Memory Alloys
}

\author{
Nevzat Sarı ${ }^{1}$, Halit Doğan ${ }^{1} *$ \\ ${ }^{1}$ Mechanical Eng. Dept., Engineering Faculty, Manisa Celal Bayar University, Campus of Şehit Prof. Dr. İlhan \\ Varank, 45140, Manisa, Turkey \\ *halit.dogan@bayar.edu.tr
}

Received: 14 December 2018

Accepted: 12 December 2019

DOI: $10.18466 /$ cbayarfbe. 497388

\begin{abstract}
:
Today, with the development of technology, different welding methods were applied for different alloys. In this work, changing of functional properties after using welding methods for NiTi alloy samples were aimed. However, two different welding methods were employed for the same alloy and results were compared to each other and commented on them. In the present study, samples were welded with TIG and Laser welding and their cross section of welded zone was examined. Then these samples were examined in optical microscope and SEM. The advantages and disadvantages of both welding methods were reported. The basic distinction of TIG and laser welded samples examined in microscope were the scale of HAZ (Heat Affected Zone) of TIG welded samples. Nevertheless, due to more thermal input was applied for materials in TIG welded parts, more molten materials were detected, or heat effects were attained in this practice. In laser welding, heat input was less, and this could be recognized from the observed micrographs. When SEM figures were investigated, While HAZ was obviously distinguished from border of welding bath and the base metal was been separated from HAZ too. The twin structures were not observed in optical microscope; for that reason, they were investigated in SEM to see these twins in laser welded area.
\end{abstract}

Keywords: NiTi, Shape Memory Alloy, Super-elastic, Twinning, Welding.

\section{Introduction}

The use of shape memory alloys has increased in recent years, thanks to its functional properties such as shape memory and super flexibility [1].

The industrial applications of smart materials were limited when first used, but their use increased rapidly. Nowadays, shape memory alloys are used in many fields such as medicine, automotive, aerospace and energy applications [2].

Shape memory alloys have two main features: Super flexibility and shape memory effect. NiTi, which is the most widely used in these alloys, has high strength and ductility properties [1]. Shape memory alloys are capable of reversible thermoelastic phase conversion. These features give them super flexibility and shape memory [3].

Martensitic transformation is induced by the applied thermomechanical loading of the austenitic phase, leading to significant inelastic stresses recovered over discharge due to inverse phase transformation of the austenitic phase. Austenite can be transformed into martensite during mechanical loading and can lead to an inflexible deformation which can be self-recovered upon discharge [4].

It has taken many years to characterize the mechanism of repeating martensitic structure due to stress and temperature of SMAs [5]. Nickel alloys; they exhibit high wear resistance, corrosion resistance, toughness and high temperature resistance [6]. Titanium (Ti) alloys are resistant to high temperatures, high corrosion resistance and stable in chemical environments [7].

Titanium and its alloys have high fatigue life, good toughness, good corrosion resistance despite their low weight. Due to these superior properties, they are frequently used in the aviation industry [8].

Nickel-Titanium alloys are shape memory materials. Smart materials; As they have good flexibility and good biocompatibility, they are widely used in many areas, from sensors to moving parts. In particular, aerospace, automotive, robotics and biomedical are some of these areas $[9,10]$. 
Celal Bayar University Journal of Science

Volume 15, Issue 4, 2019 p 415-421

Doi: $10.18466 /$ cbayarfbe. 497388

These alloys can withstand more stress in deformation discharge [11].

Tungsten Inert Gas (TIG) welding process enables high quality welded joints. Because of this superior property, it is widely used in the nuclear and thermal power plant industries, the source of different components. However, the single pass weld has a low penetration. Changes in alloying elements, negatively affects the source penetration [12].

Guoxin and colleagues compared the porous $\mathrm{NiTi}$ material produced by powder metallurgy under a pressure of 400 bar to the alloy produced by metal injection. For both methods, they examined XRD patterns and SEM micrographs and observed that larger pores were formed from the powder [13].

In another study: In NiTi alloys, the effect of copper on sintering and heat treatment was investigated [14]. Optimization of the maximum amount of copper was determined using DSC, SEM and XRD analyzes. The effect of Nd: YAG laser welding on the mechanical properties of NiTi alloys studied. They used the DSC analysis and the optical microscope to investigate the different phases in the source region with the heat affected zone [15].

The purpose of this study was to investigate the weldability of NiTi alloys and its microstructural variations in heat affected zone after welding. As a result of the microstructural variations were investigated. The possible physical deterioration after welding and also the type, magnitude and physical behaviours were observed.

\section{Materials and Methods}

\subsection{Experimental Study}

First, the employed shape memory alloys were obtained in abroad and then the welded parts were examined in optical microscope and SEM. Laser and TIG welded parts were cut into two samples by wire erosion bench perpendicular to the welding plane, and then they were prepared for optical and SEM micrographs investigation.

\subsection{Materials}

NiTi (Nitinol) shape memory alloys were employed in the present study. NiTi alloys including \%50.2 Ti were received from Memory Metalle $\mathrm{GmbH}$, Germany. The samples were polished and etched for optical and SEM micrographs investigation.

\subsection{Welding Samples Preparation}

Shape memory alloys having $9.15 \mathrm{~mm}$ diameter were milled from each sides to flatten for easy welding geometry. Then welding jaws were prepared for welding process for each facing corner.

\subsection{Samples Welding}

The milled parts were cleaned as physical and chemical process for welding. Especially the studied parts were purged via ethyl alcohol and then they were welded by TIG and Laser welding.

The ready parts for welding were fixed with a vice from the side. Then they were welded via a TIG method (using Lincoln Invertech machine) under a pure argon gas (\%99.99 purity) using 59 ampere current and the welded parts were cooled in air (Figure 1). The composition of the filling material was selected from the base metal itself in $1.5 \mathrm{~mm}$ diameter wire.

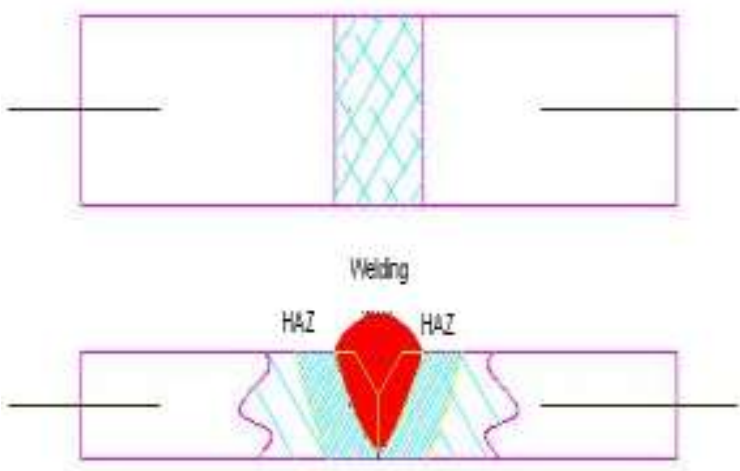

Figure 1. Symbolic illustration of TIG welded part.

NOVAPAX W40 Nd:YAG Laser welding machine was used. process was also realised using 250-300 Watt power, $8.2 \mathrm{~ms}$ time, $8.4 \mathrm{~Hz}$ frequency and 0.5 $\mu \mathrm{m}$ wavelength. The diameter of welding filling wire were used as $0.6 \mathrm{~mm}$ diameter Circular, cylindrical - fast axis \& slow axis SUSS lens was used. Pure argon (\%99.99) was also used as protecting atmosphere in this welding method. Flow rate of the shielding gas was $27 \mathrm{l} / \mathrm{min}$. Weldin was occured specimens-one side with using multiple passes. The schematic view of the welded samples was shown in Figure 2. 

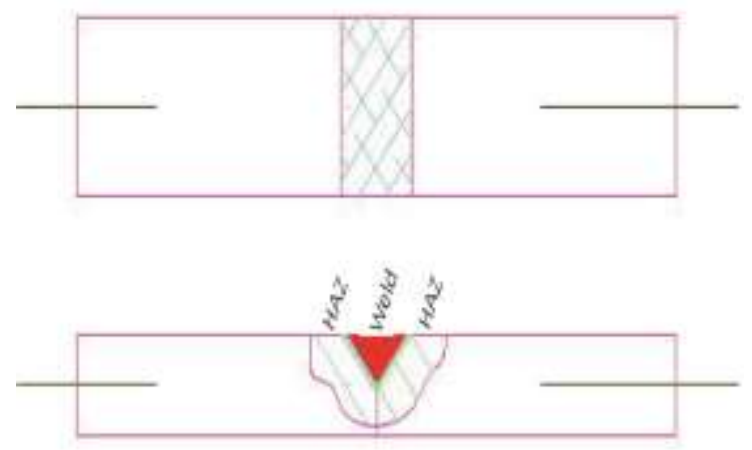

Figure 2. The schematic view of laser welded parts.

\subsection{Cut in Wire Erosion}

The laser and TIG welded specimens were cut with wire erosion machine in perpendicular to the welding plane. Very precise faces of the specimens were obtained in wire erosion and therefore polishing of them was done easily.

\subsection{Grinding, Polishing and Etching}

Centrally divided specimens were ground starting with 120 up to 1000 grit emery paper and then they were polished with 6 and $1 \mu \mathrm{m}$ diamond paste. Then these samples were etched in a solution of 10 $\mathrm{ml} \mathrm{HF}, 40 \mathrm{ml} \mathrm{HNO}_{3}$ and $50 \mathrm{ml} \mathrm{H}_{2} \mathrm{O}$ as 25 seconds.

\subsection{Investigation in Optical Microscope}

The etched specimens were inspected in optical microscope. The optical micrographs were taken from the three different area of the specimen namely base metal, heat affected zone (HAZ) and welded area. Three micrographs were illustrated in Figure 3, Figure.4 and Figure 5.

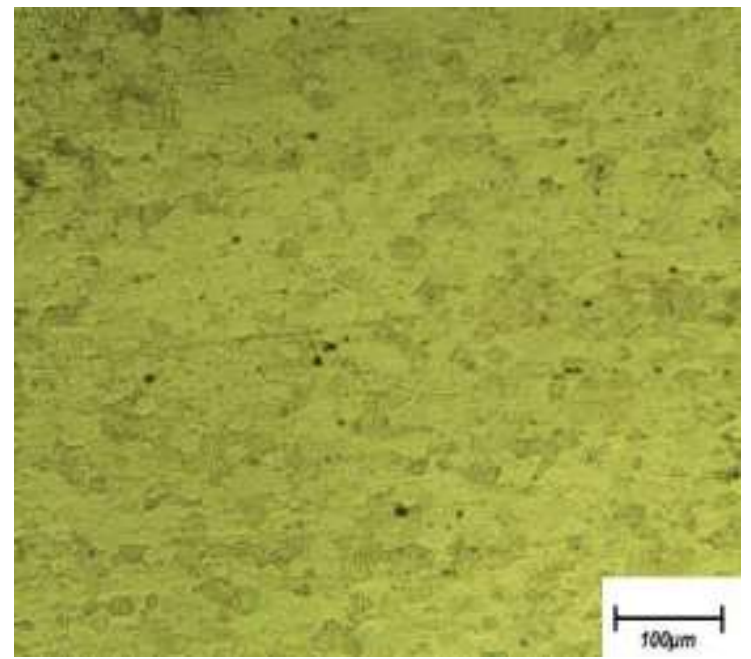

Figure 3. Microstructure of NiTi alloys (base metal).

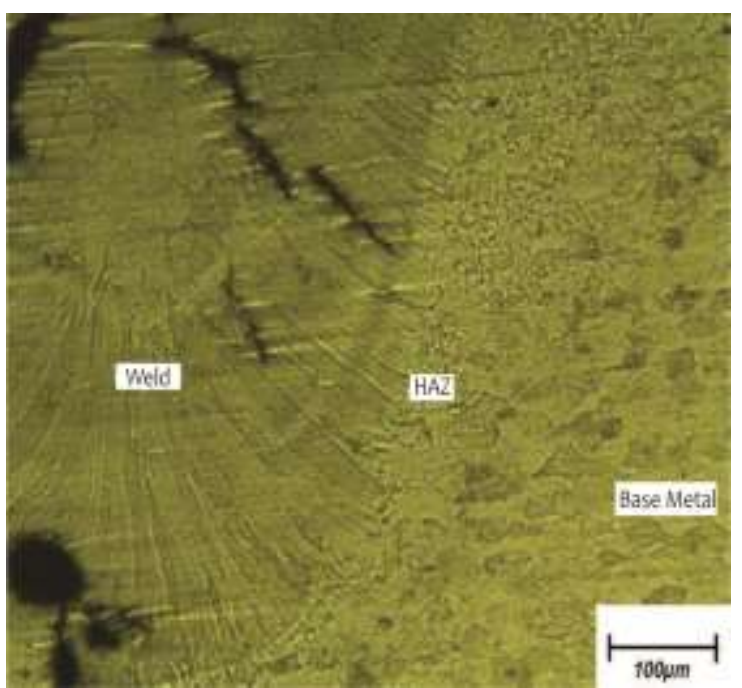

Figure 4. Base metals, HAZ and weld in laser welded samples.

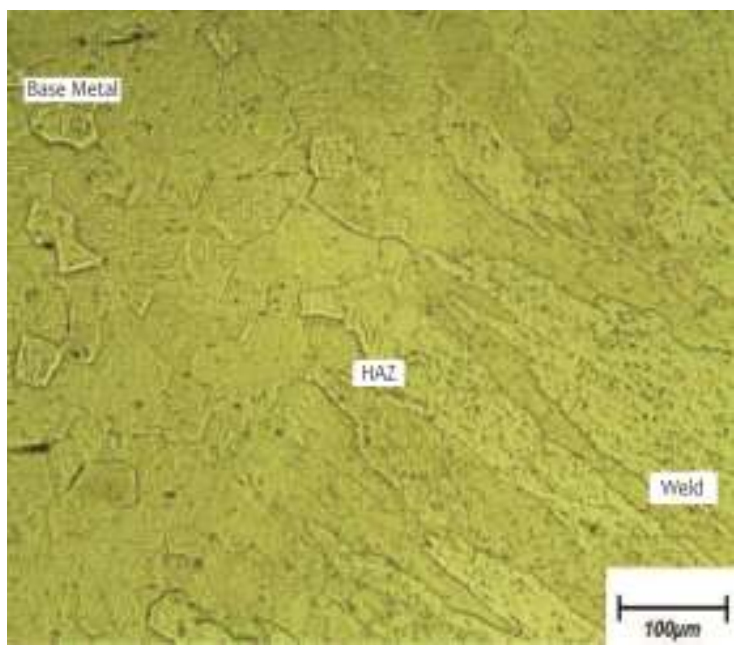

Figure 5. Base metals, HAZ and weld in TIG welded samples.

\subsection{SEM Analysis}

Some details in microstructural variations were examined in SEM. Various micrographs were taken from the weld metal and HAZ. HAZ of laser welded sample SEM view was shown in Figure 6 
Celal Bayar University Journal of Science

Volume 15, Issue 4, 2019 p 415-421

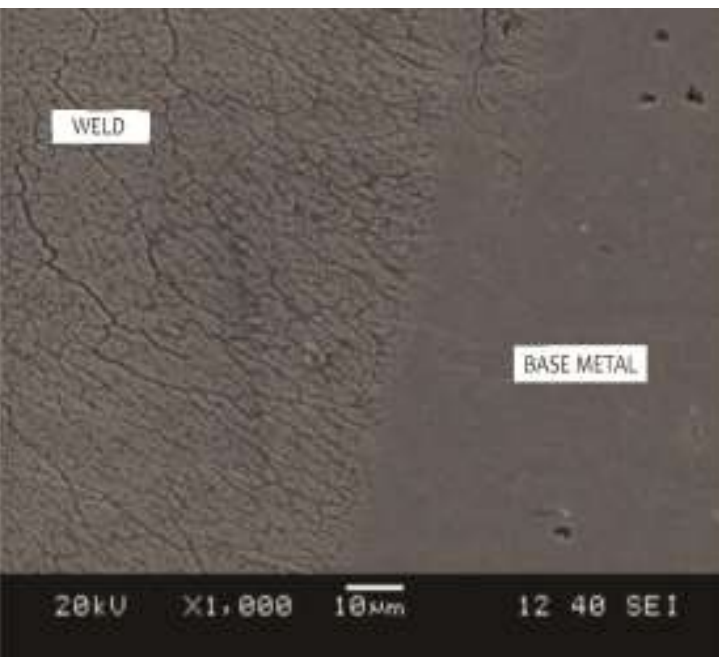

Figure 6. SEM view of welded area in laser welded samples.

\section{Results}

Welding performance of NiTi alloys are low. Therefore, it is needed to pay attention for environmental conditions and welding parameters during the welding. Also, preventing oxidation is important for the safe weldability. Laser welding should be carried out in argon atmosphere or vacuum to protect the metal in welded zone. As a result, the weld metal can be protected from oxidation and the better welding performance can be obtained.

\subsection{Welded NiTi Data}

The fundamental difference of TIG and laser welded samples observed in microscope were the magnitude of HAZ area of TIG welded part. In fact, identical welding slot was opened for both welding methods. However, due to more thermal inputs were applied for materials in TIG welded parts, more molten materials were observed or heat effects were obtained in this process.

Grain elongations and orientations changing depended on welding advancing direction and welding current were observed in both welding methods.

In Figure 7, oriented grain boundaries were observed in welded area. If welding process was not done under proper conditions, cracks started to form along the oriented grain boundaries when the metallic part begins to cool [16].

The variation of TIG welding in microstructure was more than the laser weldings [17] and this was observed by naked eye and microscopes.

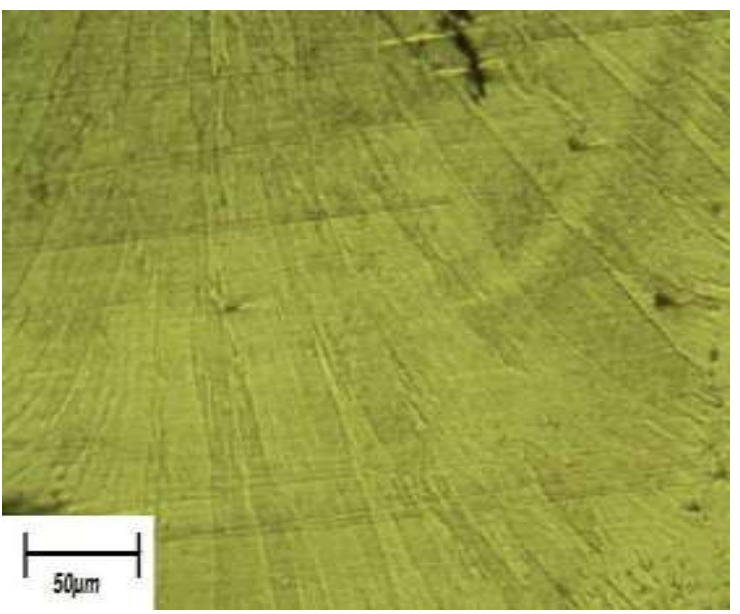

Figure 7. Directed grain boundaries in welded area.
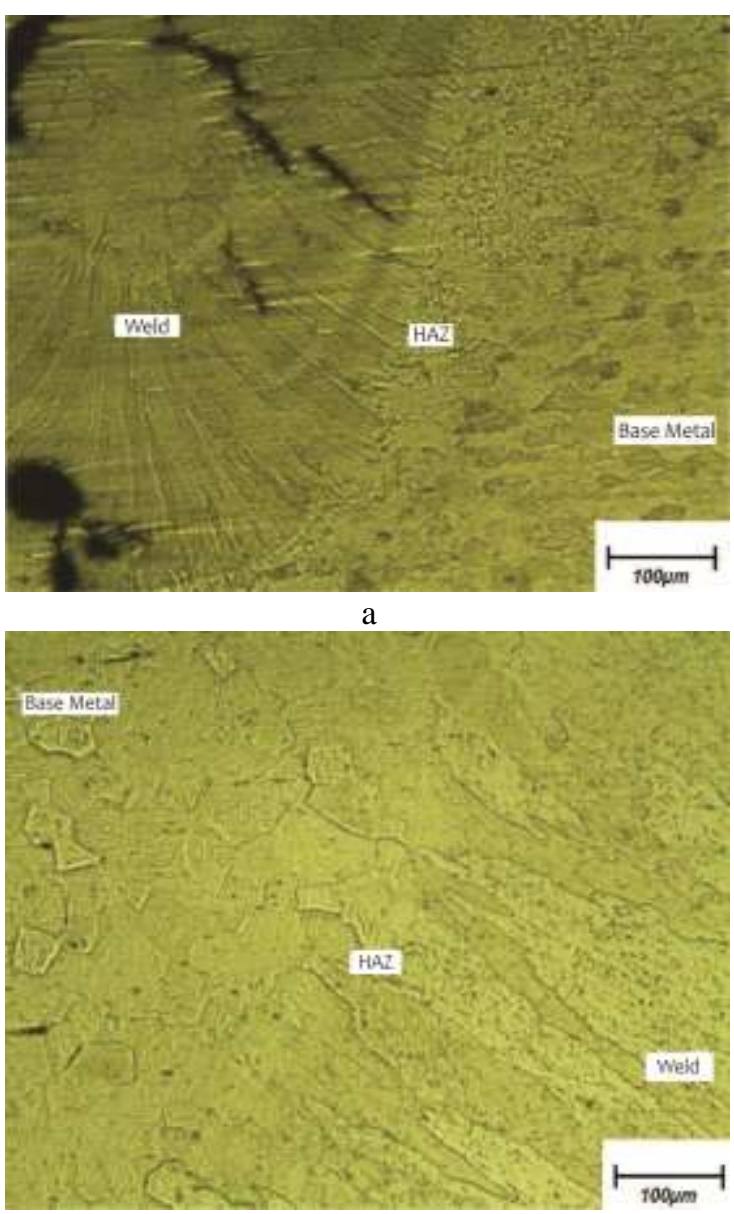

b

Figure 8. Cross section of welded zone of $\mathrm{NiTi}$ alloys (a) Laser, (b) TIG.

The microstructure in Figure 8 was taken from (HAZ) the heat affected zone in welded area. 


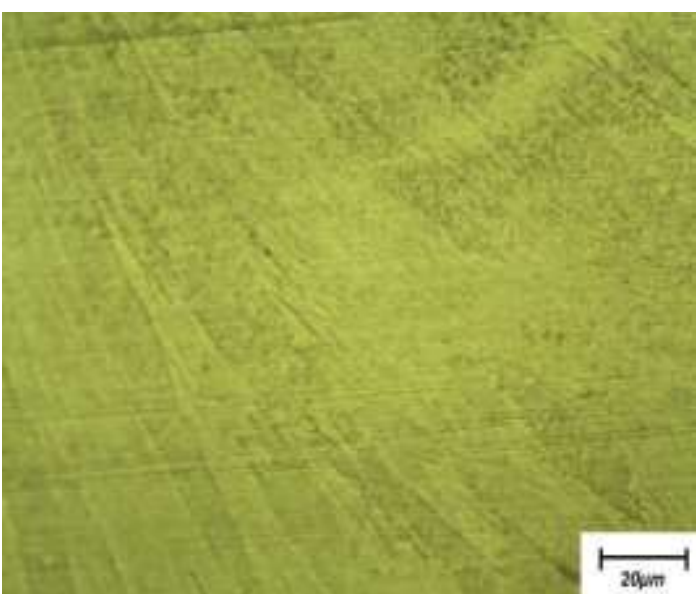

Figure 9. Welded area in laser welding.

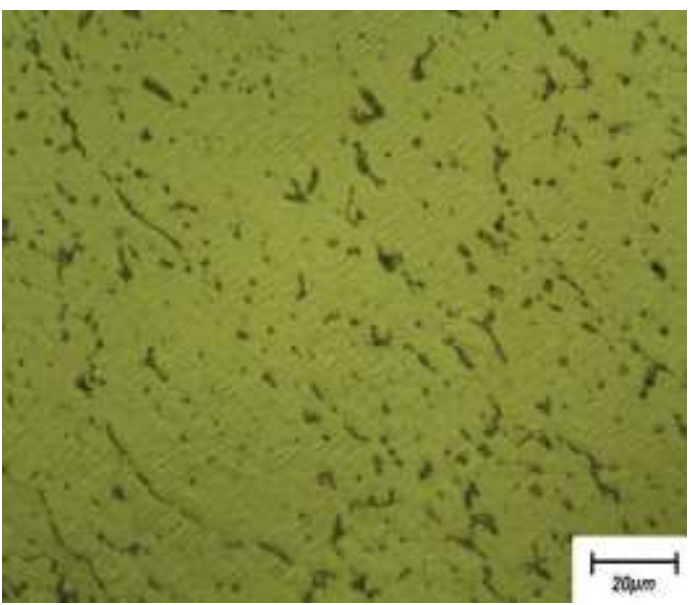

Figure 10. Welded area in TIG welding.

It was seen from Figure 9 and Figure 10 that the microstructure was affected high temperatures due to both welding. However, laser welded parts had less influence than the TIG welded parts, and this could also be visible in 100X magnifications [18]. Welded area of laser welded samples in 100X magnifications was seen in Figure 11. Also, the view of welded area was illustrated in Figure 12 for TIG welding.

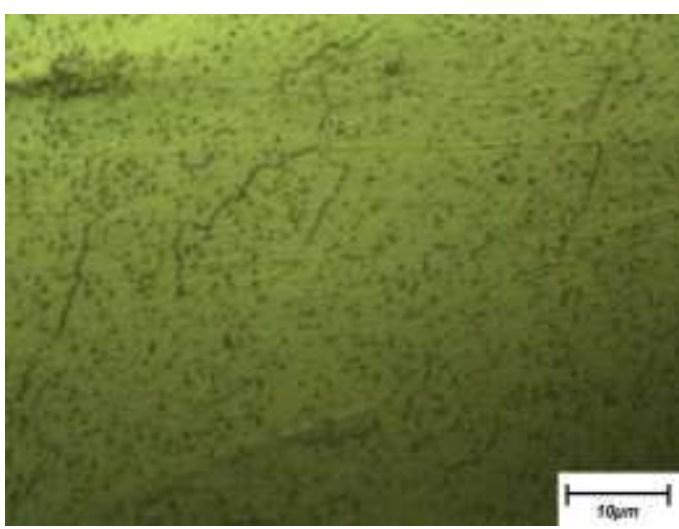

Figure 11. Microstructure in laser welded area.

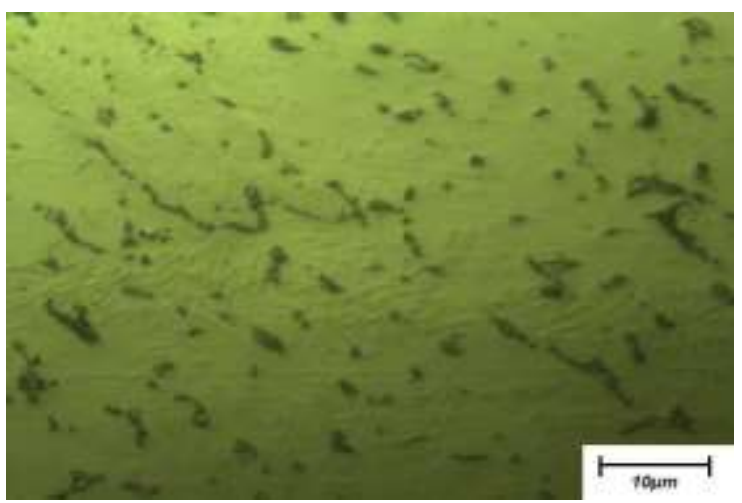

Figure 12. View of base metal area in TIG welding.

Due to high thermal imput occured fine grains in laser welded part, twins reforming after cooling could not be seen in optical microscope but this kind of twins were seen TIG welded parts after the welded area cools.

In Fig. 12, the view of base metal in TIG process was seen. Grain boundaries and twins were clearly visible. In Fig. 13 reformed twin structures were detectable in welded area. Even if the grains were twinned in welded zone, the formed twins had been limited effect on base metal hence elongation of grain boundaries formed due to welding current.

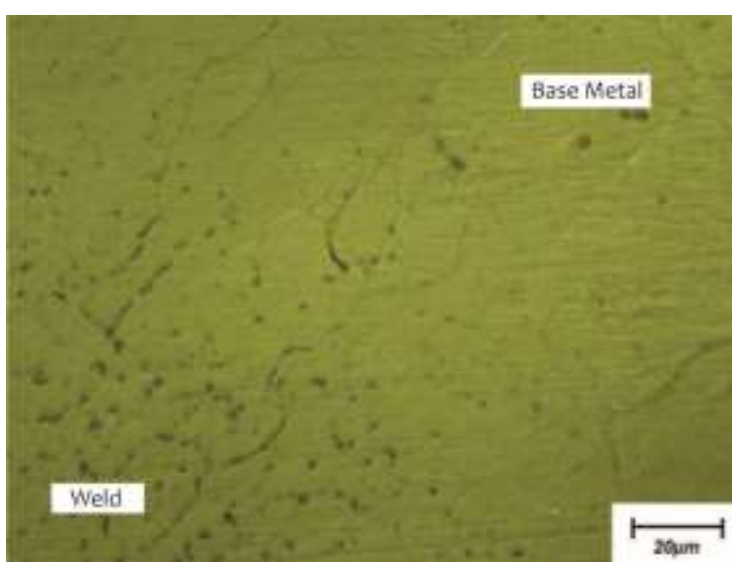

Figure 13. Weld-base metal area in TIG welding.

\subsection{SEM Micrographs of Welded NiTi Alloys}

Some welded parts were investigated in SEM to see the microstructural variations of the samples. Some micrographs were observed in SEM and they were illustrated in Figures 14 and Figure 15. 


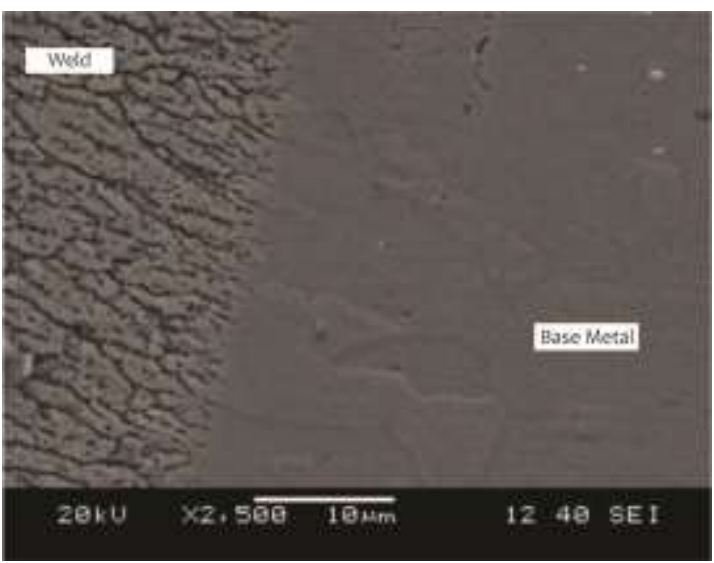

Figure 14. SEM view of weld-base metal area in laser welded NiTi alloys.

It was observed in Figure 14 that base metal was tougher and ductile comparing to welded zone, therefore fracture and tractive disorders started and occured in front area of HAZ in case of physical strain. In laser welding, heat input was less and this could been understood from the micrographs (Figure 15- Figure 16). Since HAZ area was clearly distinguished and welding border zone was separated from the base metal.

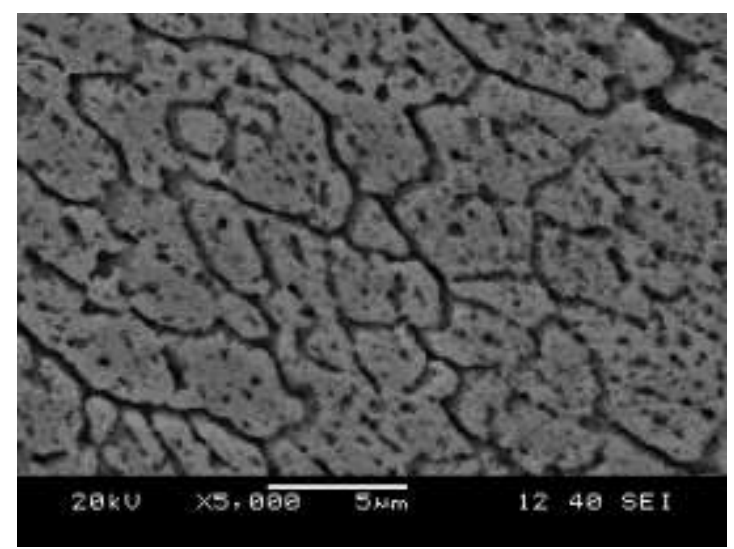

Figure 15. SEM welded area of laser welding.

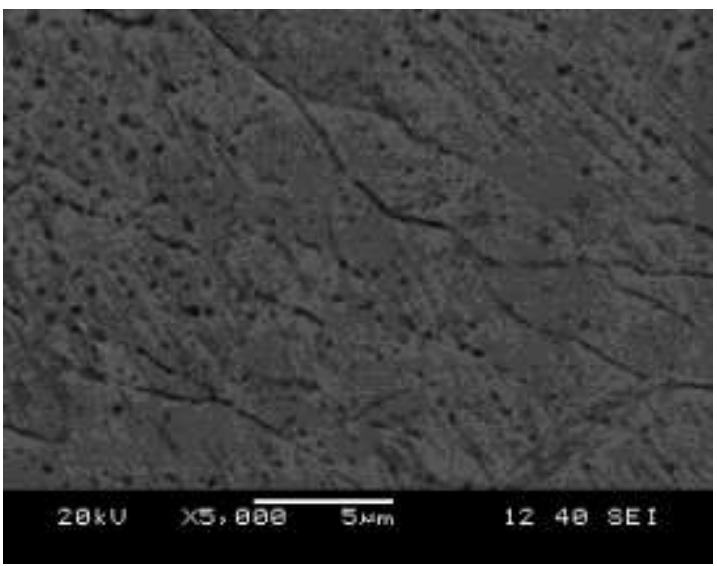

Figure 16. SEM view of HAZ in laser welding.
The twin structures were not seen in optical microscope; therefore they were investigated in SEM to see these twins in laser welded area (Figure 16). The twins formed in this area were promising about functional and mechanical properties of materials; however the positive effect of twins into mechanical properties were not noticeable due to microstructural variation in welded zone. An SEM view of HAZ area of laser welded part was seen in Figure 17. It was seen in this micrograph that welding deformed the microstructure. In Figure 18, SEM view of the TIG welded part was shown after welding process.

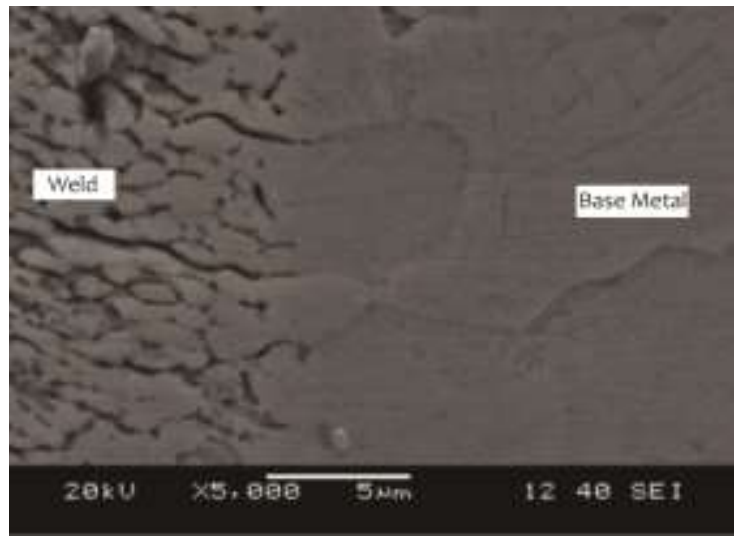

Figure 17. SEM view in laser welded area.

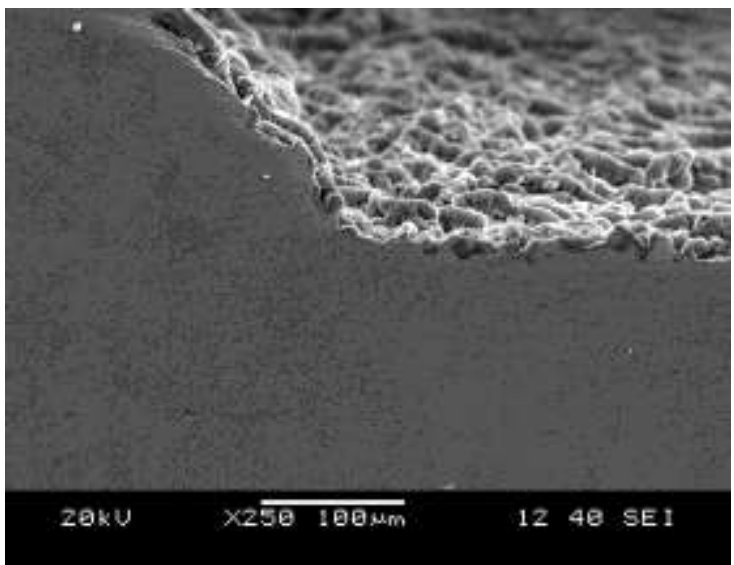

Figure 18. SEM view in TIG welded part.

\section{Conclusions}

The welding of shape memory alloys is not widespread application area due to its high cost. This application can be used only in scientific investigations, space industry, biomedical tools and aircraft industry and they are flourished due to their mechanical and functional properties $[19,20]$. As a result of the experimental studies, the following conclusions can be drawn: 
Celal Bayar University Journal of Science

Volume 15, Issue 4, 2019 p 415-421

Doi: $10.18466 /$ cbayarfbe.497388

a. The welding of NiTi alloys was successfully done by TIG and laser welding and their cross section of welded zene was examined in the welded zone.

b. As a result of the welding, a variation in microstructure of materials was observed weldment, HAZ and base metal through optical and scanning electron microscope.

c. In laser welding, heat input was less and this could been understood from the observed optical and SEM micrographs. Since HAZ area was clearly distinguished and welding border zone was separated from the base metal.

d. In laser welding, the microstructure was less affected than the TIG welding

\section{Acknowledgement}

This project was financially supported by "Scientific Research Project Office of Manisa Celal Bayar University" under grant number 2007-072.

\section{Ethics}

There are no ethical issues after the publication of this manuscript.

\section{References}

1. Oliveira J P, Miranda R M, Braz Fernandes F.M. 2017. Welding and Joining of NiTi Shape Memory Alloys. A Review, Progress in Materials Science; 412-466.

2. Mehrpouya M, Gisario A, Mohammad E. 2018. Laser welding of NiTi shape memory alloy. Journal of Manufacturing Processes; 31: 162-186.

3. Jani. J.M.; Leary M.; Subic A.; Gibson M.A.; Mohd J.J.; Leary M.; Subic A.; Gibson M.A. A review of shape memory alloy research, applications and opportunities, Materials Design, 2014; 56, 1078-1113.

4. Patoor E, Lagoudas D.C, Entchev P.B, Brinson L.C, Gao X. 2006. Shape memory alloys, part I: general properties and modeling of single crystals. Mechanical Materials; 38: 391-429.

5. Sun Y, Luo J, Zhu J. 2018. Phase field study of the microstructure evolution and thermomechanical properties of polycrystalline shape memory alloys: Grain size effect and rate effect. Computational Materials Science; 145: 252-262.

6. Özgün Ö, Yılmaz R, Gülsoy H.Ö, Fındık F. 2015. The effect of aging treatment on the fracture toughness and impact strength of injection molded Ni-625 superalloy parts. Materials Characterization; $108:$ : -15 .
7. Cao S, Xinhua W, et all. 2018. Role of martensite decomposition in tensile properties of selective laser melted Ti6Al-4V. Journal of Alloys and Compounds; 744: 357-363.

8. Wang S.Q, Liu J.H, Chen D.L. 2014. Effect of strain rate and temperature on strain hardening behavior of a dissimilar joint between Ti-6Al-4V and Ti17 alloys. Materials and Design; 56: 174-184

9. Mohd J.J, Leary M, Subic A, Gibson M.A. 2014. A review of shape memory alloy research, applications and opportunities. Materials and Design; 56: 1078-1113.

10. Saedi S, Sadi A, Taheri M, Shayesteh N. 2017. Texture, aging, and superelasticity of selective laser melting fabricated Ni- rich NiTi alloys. Materials Science Engineering A; 686: 110.

11. Machado G, Louche H, Alonso T, Favier D. 2014 Superelastic cellular NiTi tube-based materials: Fabrication, experiments and modeling. Materials and Design; 65: 212-220.

12. Vidyarthy R.S, Dwivedi D.K. 2018. Microstructural and mechanical properties assessment of the P91 A-TIG weld joints. Journal of Manufacturing Processes; 31: 523-535.

13. Guoxin H, Lixiang Z, Yunliang F, Li Yanhong. Fabrication of high porous NiTi shape memory alloy by metal injection molding; School of Mechanical \& Power Engineering, Shanghai Jiaotong University Press: Shanghai, China, 2008; pp 200-240.

14. Goryczka T, Humbeeckb J.V. 2008. NiTiCu shape memory alloy produced by powder technology. Journal of Alloys and Compounds; 456: 194-200.

15. Razorenov S.V, Garkushin G.V, Kanel G.I, Kashin O.A, Ratochka I.V. 2011. Behavior of the nickele titanium alloys with the shape memory effect under conditions of shock wave loading. Physic. Solid State; 53: 824-829.

16. Comer, A, \& Looney, L. 2006. Crack propagation resistance of Zeron 100 weld metal fabricated using the GTA and SMA welding processes. Theoretical and applied fracture mechanics; 45(2): 139-147.

17. Tuissi, A, et al. 1999. Effect of Nd-YAG laser welding on the functional properties of the Ni-49.6 at.\% Ti. Materials Science and Engineering A; 273: 813-817.

18. Falvo, A. Termomechanical characterization of NickelTitanium Shape Memory Alloys, Universita Della Calabria Press: Italy, 2007; pp 43-47.

19. Falvo, A, Furgiuele, F. M, \& Maletta, C. 2005. Laser welding of a NiTi alloy: Mechanical and shape memory behaviour. Materials. Science and Engineering A; 412(1-2): 235240 .

20. Hesse, T, Ghorashi M, Inman D.J, Intel, J. 2004 Shape Memory Alloy in Tension and Compression and its Application as Clamping-Force Actuator in a Bolted Joint. Materials Systems Structure;15: 577. 